\title{
HUBUNGAN FAKTOR-FAKTOR PEMBERIAN ASI EKSLUSIF PADA IBU BEKERJA DI RSU BUDI KEMULIAAN
}

\section{CORRELATION OF EXCLUSIVE BREASTFEEDING AMONG WORKING MOTHERS AT BUDI KEMULIAAN HOSPITAL}

\author{
Entin Sutrini, Hilma Aini Aulia \\ Sekolah Tinggi Ilmu Kesehatan Budi Kemuliaan \\ Korespondensi : entin.sutrini58@gmail.com
}

\begin{abstract}
The role of women in the world of work cannot be ignored. Based on a 2013 Central Statistics Agency (BPS) survey, the number of women's labor force continues to increase every year. Currently, 114 million people (94\%), 38\% of them are female workers (43.3 million people) of whom 25 million are in the productive age. The return of working mothers is one of the factors that causes the rate of breastfeeding to decrease. This study aims to find out the factors of exclusive breastfeeding in working mothers. This research uses analytical methods with a latitude-cut approach. The data used is primary data using questionnaires and direct observation. Determination of the number of samples using lemesshow formula based on nipic visits in polyclinics on the 2nd and 3rd floor of Budi Kemuliaan Hospital in May 2019 as many as 51 respondents. Data analysis used is univariate and bivariate analysis. Analysis results indicate the type of work has not correlation with exclusive breastfeeding however the breastfeeding skills have $41.2 \%$ of mothers skilled enough breastfeeding of 21 respondents, but some mothers said has lack of understanding on breastfeeding management. The results of the analysis are statistically meaningful relationships (P0.04). Caring skills and communication skills from professionals healthcare as primary counsellors are required, so the mother is comfortable and baby's is healthy.
\end{abstract}

Keywords: Exclusive Breastfeed, Working Mothers, Breastfeed Skills.

\begin{abstract}
ABSTRAK
Peran perempuan dalam dunia kerja tidak dapat diabaikan. Berdasarkan survei Badan Pusat Statistik (BPS) tahun 2013, jumlah angkatan kerja wanita terus meningkat setiap tahunnya. Saat ini dari 114 juta jiwa (94\%), 38\% diantaranya adalah pekerja perempuan (43,3 juta jiwa) yang 25 juta diantaranya berada pada usia reproduktif. Kembalinya ibu bekerja merupakan salah satu faktor yang menyebabkan angka pemberian ASI menurun. Penelitian ini bertujuan untuk mengetahui hubungan faktor-faktor pemberian ASI eksklusif pada ibu yang bekerja. Penelitian ini menggunakan metode analitik dengan pendekatan secara potong lintang. Data yang digunakan adalah data primer dengan menggunakan kuesioner dan observasi langsung. Penentuan jumlah sampel menggunakan rumus lemesshow berdasarkan kunjungan nifas di Poliklinik lantai 2 dan 3 RSU Budi Kemuliaan periode Mei tahun 2019 sebanyak 51 responden. Analisis data yang digunakan adalah analisis univariat dan bivariat. Hasil analisis menunjukkan jenis pekerjaan tidak memiliki hubungan dengan pemberian ASI Eksklusif melainkan keterampilan menyusui ibu sebesar $41,2 \%$ ibu cukup terampil menyusui dengan jumlah 21 responden, namun sebagian ibu mengatakan kurangnya pemahaman mengenai manajemen ASI. Hasil analisis terdapat hubungan bermakna secara statistik (P 0,04).
\end{abstract}


Sehingga diperlukan keterampilan interpersonal (caring) dan keterampilan komunikasi dari tenaga kesehatan sebagai konselor ASI primer, agar ibu nyaman bayi pun sehat.

Kata Kunci: Pemberian ASI Eksklusif, Ibu Bekerja, Keterampilan Menyusui.

\section{PENDAHULUAN}

Organisasi Kesehatan Dunia (WHO) dan Kementerian Kesehatan merekomendasikan bahwa bayi disusui segera setelah lahir dan tidak diberi makanan apapun selain ASI selama 6 bulan pertama kehidupan, tidak diberikan air, ataupun makanan lain, hanya ASI saja. Dari 6 bulan hingga 2 tahun, ASI harus tetap diberikan bersama dengan makanan pendamping ASI yang aman dan bergizi (UNICEF, 2016).

Dalam rangka mendukung pemberian ASI eksklusif, sejak 1 Maret 2012 telah disahkan Peraturan Pemerintah Nomor 33 Tahun 2012 tentang ASI Eksklusif. Beberapa yang dibahas antara lain hak bayi mendapatkan ASI, hak ibu untuk menyusui, kewajiban fasilitas kesehatan untuk memfasilitasi pemberian ASI Eksklusif, dan kewajiban tempat kerja memberikan tempat menyusui.

Berdasarkan Peraturan Pemerintah Nomor nomor 33 tahun 2012 Air Susu Ibu (ASI) eksklusif adalah ASI yang diberikan kepada bayi sejak dilahirkan selama enam bulan, tanpa menambahkan dan/atau mengganti dengan makanan atau minuman lain kecuali obat, vitamin, dan mineral (Pusat Data Indonesia, 2016).
Berdasarkan survei Badan Pusat Statistik (BPS) tahun 2013, Jumlah angkatan kerja wanita terus meningkat setiap tahunnya. Saat ini dari 114 juta jiwa (94\%), 38\% diantaranya adalah pekerja perempuan (43,3 juta jiwa) yang 25 juta diantaranya berada pada usia reproduktif (Kementrian Kesehatan RI, 2015).

Di dunia, 44\% bayi baru lahir melakukan inisiasi menyusu dini di 1 jam pertamanya. Angka yang diharapkan dunia untuk pemenuhan ASI sebanyak 70\%. Data yang tercatat dari 129 negara, hanya 22 saja yang mendekati target.Keseluruhan data ASI Eksklusif untuk bayi dibawah 6 bulan sebesar $40 \%$ dan hanya 23 negara yang mencapai angka 60\% (World Health Organization, 2017).

Capaian ASI eksklusif di Indonesia sudah melampaui target Renstra yaitu sebesar 44\%. Berdasarkan laporan SDKI tahun 2017 pencapaian ASI eksklusif adalah 61,33\%. Persentase tertinggi cakupan pemberian ASI Eksklusif terdapat pada Nusa Tenggara Barat (87,35\%), sedangkan persentase terendah terdapat pada Papua (15,32\%). Wilayah DKI Jakarta mencapai $67.40 \%$ dari $100 \%$ dan masih ada lima provinsi yang belum mencapai target 
Renstra tahun 2017 seperti Banten, Maluku, Sulawesi Barat dan wilayah Papua.

Salah satu faktor yang mempengaruhi rendahnya pemberian ASI Eksklusif di Indonesia adalah belum semua tempat kerja menyediakan ruang ASI (Pusat Data Indonesia, 2018).

Kembalinya ibu bekerja merupakan salah satu faktor yang menyebabkan angka pemberian ASI menurun. Hal ini dapat diketahui dari The UK National Infant Feeding yang dilakukan pada tahun 2000 dengan melibatkan sampel 9.500 ibu yang melahirkan bayi di Inggris, menunjukkan bahwa sebanyak 39 persen alasan berhenti menyusui karena kembalinya ibu bekerja (Sisca Rahadian, 2017).

Tujuan penelitian ini untuk mengetahui faktor-faktor pemberian ASI Eksklusif pada Ibu yang bekerja yang akan dilakukan di Poliklinik RSU Budi Kemuliaan.

\section{METODE}

Penelitian ini menggunakan metode analitik dengan pendekatan potong lintang. Data yang digunakan adalah data primer dengan menggunakan kuesioner dan observasi langsung dalam pengumpulan data yang diteliti di Poliklinik RSU Budi Kemuliaan periode Mei-Juni tahun 2019.

Metode sampling yang digunakan pada penelitian ini adalah metode
Purposive Sampling. Cara pengumpulan data dilakukan dengan menggunakan data primer dengan cara memberikan kuesioner dan melakukan observasi ibu saat menyusui ketika kunjungan ulang. Analisis data memakai analisi univariat yaitu melakukan analisa berdasarkan distribusi frekwensi mendeskripsikan setiap variabelnya dan Analisis Bivariat menjelaskan hubungan anatara variabel independen dengan variabel dependent dibuktikan dengan uji Chi Square. Pelaksanaan penelitian ini melibatkan peneliti utama sejumlah 1 orang, dan anggota peneliti sejumlah 1 orang, proses pelaksanaan penelitian dimulai dengan studi pendahuluan, izin penelitian dengan Bidang penelitian Lembaga Kesehatan Budi Kemulian No. Surat: 043/TU.03/STIKBK/01/VII/2020. Untuk selanjutnya dilakukan penelitian.

\section{HASIL DAN PEMBAHASAN}

Responden dalam penelitian ini sejumlah 51 orang. Hasil penelitian ini sebagai berikut:

Tabel 1. Gambaran Karakteristik Ibu Bekerja Yang Berhubungan Dengan ASI Ekslusif

\begin{tabular}{lll}
\hline \multicolumn{1}{c}{ Variabel } & Frekuensi & Persentase \\
\hline Pendidikan & & \\
SMA & 30 & $59 \%$ \\
Perguruan Tinggi & 21 & $41 \%$ \\
Usia & & \\
$\quad<20$ tahun & 9 & $18 \%$ \\
$20-35$ tahun & 35 & $68 \%$ \\
$>35$ tahun & 7 & $14 \%$ \\
& & \\
\hline
\end{tabular}




\begin{tabular}{lll}
\hline Variabel & Frekuensi & Persentase \\
Pekerjaan & & \\
$\quad$ Kary Swasta & 31 & $61 \%$ \\
PNS & 11 & $21 \%$ \\
$\quad$ Wiraswasta & 7 & $14 \%$ \\
$\quad$ Buruh & 2 & $4 \%$ \\
Pengetahuan & & \\
$\quad$ Baik & 32 & $63 \%$ \\
$\quad$ Cukup & 17 & $31 \%$ \\
$\quad$ Kurang & 2 & $6 \%$ \\
Dukungan sosial & & \\
$\quad$ Baik & 38 & $75 \%$ \\
$\quad$ Cukup & 11 & $21 \%$, \\
$\quad$ Kurang & 2 & $4 \%$ \\
\hline
\end{tabular}

baik dengan jumlah 38orang (75\%), cukup 11 orang (21\%), dan kurang 2orang (4\%). Keterampilan menyusui ibu cukup dengan jumlah responden 21 (41\%), keterampilan Baik dengan jumlah responden 18 (35\%), keterampilan kurang 12 responden (24\%).

Berdasarkan tabel 1 diperoleh hasil kategori usia ibu menyusui yang bekerja di RSU Budi Kemuliaan terbanyak didapatkan usia 20-30 tahun sebanyak 35 responden (68\%) dan yang terkecil didapatkan usia > 35 tahun sebanyak 7 responden (14\%). Berdasarkan pendidikan terakhir yang paling banyak adalah SMA 30 orang (56\%), lalu dilanjutkan Perguruan tinggi 21 orang (38\%), lalu pendidikan terakir SMP dan SD tidak ada. Pekerjaan ibu menyusui yang bekerja di RSU Budi Kemuliaan didapatkan ibu yang memiliki pekerjaan sebagai karyawan swasta 31orang (61\%), PNS sebanyak 11 orang (21\%), wiraswasta 7 orang (14\%) dan Buruh sebanyak 2 orang (4\%). Pengetahuan Baik dengan jumlah 32orang (63\%), pengetahuan cukup 17 orang (31\%), dan pengetahuan kurang 2orang (6\%). Dukungan sosial pada ibu menyusui yang bekerja di RSU Budi Kemuliaan dapat dikategorikan hasil analisis terbesar yaitu dukungan sosial yang

Tabel 2. Hubungan ASI ekslusif berdasarkan usia,pekerjaan, pendidikan, pengetahuan,dan dukungan sosial

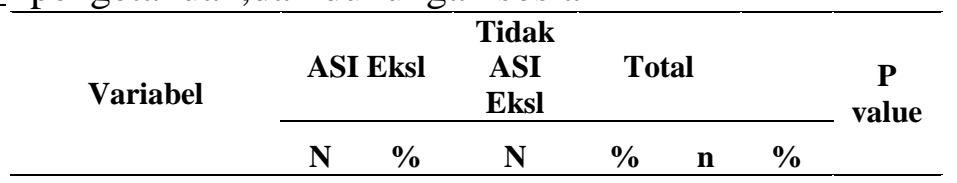

\begin{tabular}{|c|c|c|c|c|c|c|c|}
\hline Usia & & & & & & & \\
\hline$<20$ Tahun & 0 & 0 & 9 & 23.1 & 9 & 17.7 & \multirow{3}{*}{0,116} \\
\hline 20 -35Tahun & 9 & 23,1 & 26 & 66,7 & 35 & 68.6 & \\
\hline$>35$ Tahun & 3 & 5.9 & 4 & 7.8 & 7 & 13.7 & \\
\hline \multicolumn{8}{|l|}{ Pekerjaan } \\
\hline Kary Swasta & 8 & 15.7 & 23 & 45.1 & 31 & 60.8 & \multirow{4}{*}{0,09} \\
\hline PNS & 3 & 5.9 & 8 & 15.9 & 11 & 21.6 & \\
\hline Wiraswasta & 1 & 1.9 & 6 & 11.8 & 7 & 13.7 & \\
\hline Buruh & 0 & 0 & 2 & 3.9 & 2 & 3.9 & \\
\hline \multicolumn{8}{|l|}{ Pendidikan } \\
\hline Tamat SD & 0 & 0 & 0 & 0 & 0 & 0 & \multirow{4}{*}{0,04} \\
\hline Tamat SMP & 0 & 19.7 & 0 & 0 & 0 & 0 & \\
\hline Tamat SMA & 4 & 7.8 & 26 & 50.1 & 30 & 58.8 & \\
\hline $\begin{array}{l}\text { Tamat Perguruan } \\
\text { Tinggi }\end{array}$ & 8 & 15.7 & 13 & 25.5 & 21 & 41.2 & \\
\hline \multicolumn{8}{|l|}{$\begin{array}{l}\text { Tingkat } \\
\text { pengetahuan }\end{array}$} \\
\hline Baik & 9 & 17.6 & 23 & 45.1 & 32 & 62.7 & \multirow{3}{*}{0,12} \\
\hline Cukup & 3 & 5.9 & 14 & 27.5 & 17 & 33.4 & \\
\hline Kurang & 0 & 0 & 2 & 3.9 & 2 & 3.9 & \\
\hline \multicolumn{8}{|l|}{ Dukungan Sosial } \\
\hline Baik & 11 & 21.6 & 27 & 52.9 & 38 & 74.5 & \multirow{3}{*}{0,28} \\
\hline Cukup & 1 & 1.9 & 10 & 19.6 & 11 & 21.6 & \\
\hline Kurang & 0 & 0 & 2 & 3.9 & 2 & 3.9 & \\
\hline \multicolumn{7}{|l|}{$\begin{array}{l}\text { Keterampilan } \\
\text { menyusui }\end{array}$} & \multirow[t]{4}{*}{0,04} \\
\hline Baik & 11 & 21.6 & 27 & 52.9 & 38 & 74.5 & \\
\hline Cukup & 1 & 1.9 & 10 & 19.6 & 11 & 21.6 & \\
\hline Kurang & 0 & 0 & 2 & 3.9 & 2 & 3.9 & \\
\hline
\end{tabular}


Hasil analisis ada hubungan antara pemberian ASI Eksklusif dengan keterampilan ibu menyusui pada ibu yang bekerja dengan nilai P 0,04. Menurut penelitian Handayani dkk dalam Jurnal Kedokteran dan Kesehatan Indonesia tahun 2016 tentang "The association between breastfeeding technique and knowledgewith exclusive breastfeeding".

Sebagian besar ibu yang memilih tidak menyusui bayi nya umumnya bukan karena masalah kondisi fisik namun kurangnya konseling laktasi yang adekuat salah satunya adalah konseling tentang teknik menyusui.

Dengan demikian diperlukan keterampilan interpersonal (caring) dan keterampilan komunikasi dari tenaga kesehatan sebagai konselor ASI primer. Peran konselor diantaranya sebagai konsultan, agen pengubah, agen prevensi primer dan terakhir serta sebagai manajer yang mengatur keberhasilan adaptasi kearah yang positif atau arah negatif (Namora, 2014).

Hasil analisis ada hubungan antara pemberian ASI Eksklusif dengan jenjang Pendidikan ibu menyusui yang bekerja dengan nilai $\mathrm{P}$ 0,04. Berdasarkan hasil penelitian, frekuensi pendidikan ibu menyusui bekerja di RSU Budi Kemuliaan berdasarkan pendidikan terakhir yang paling banyak adalah SMA sebanyak 30 orang (56\%), dilanjutkan Perguruan tinggi 21 orang $(38 \%)$. Saat penelitian tidak didapatkan responden dengan pendidikan terakhir SMP dan SD. Demikian dengan hasil penelitian oleh I Gusti Putu Felix tentang hubungan antara karakteristik ibu dan pemberian ASI eksklusif tahun 2013 memperlihatkan respon negative bahwa tidak terdapat hubungan antara pendidikan terakhir dengan pemberian ASI eksklusif. Sebesar 3,4\% ibu dengan pendidikan rendah dan tidak sekolah memberikan ASI eksklusif sementara ibu dengan pendidikan menengah dan tinggi tidak ada yang memberikan ASI eksklusif.

Tingkat pendidikan yang tinggi merupakan salah satu faktor dalam membentuk pengetahuan yang luas sehingga seseorang memiliki wawasan yang lebih luas dan mudah menerima informasi. Ibu berpendidikan tinggi juga lebih terpapar informasi dari pusat kesehatan mengenai manfaat menyusui.Meskipun tingkat pendidikan mempengaruhi pengetahuan seseorang, pengetahuan tetap dapat diperoleh di luar pendidikan normal (Notoatmojo, 2010).

Hasil analisis hubungan antara pemberian ASI Eksklusif ibu bekerja dengan dukungan social yang diberikan pada ibu oleh suami, keluarga, maupun lingkungan tempat bekerja menunjukkan 
tidak adanya hubungan bermakna secara statistik antara dukungan sosial yang diterima ibu dengan pemberian ASI secara Eksklusif pada ibu yang bekerja dengan nilai P 0,28. Dari hasil penelitian gambaran pemberian ASI Eksklusif pada ibu yang bekerja di Poliklinik RSU Budi Kemuliaan didapatkan kategori dukungan sosial yang baik sebesar 75\%. Dalam hal ini diharapkan dapat mengurangi potensi penurunan produksi ASI yang dapat semakin mempersulit pemberian ASI pada ibu bekerja. Ditinjau dari analisis hubungan antara pemberian ASI Eksklusif ibu bekerja dengan dukungan soial yang diberikan pada ibu tidak memiliki hubungan bermakna secara statistic dengan nilai P 0,28 karena masih terdapat $11 \mathrm{ibu}$ dari $38 \mathrm{ibu}$ yang mendapatkan dukungan sosial yang baik memberikan ASI eksklusif kepada bayinya.

Demikian dijelaskan dalam penelitian AnggaSisca Rahardian tahun 2017 tentang pemenuhan Hak ASI eksklusif di kalangan ibu bekerja: peluang dan tantangan memiliki keterkaitan antara dukungan sosial terhadap pemberian ASI eksklusif pada ibu bekerja. Selain fasilitas berupa ruang menyusui dan peralatan lainnya, lingkungan sosial merupakan hal yang tidak dapat diabaikan. Diterimanya kegiatan menyusui di tempat bekerja dapat meminimalisir tekanan yang dialami ibu bekerja untuk dapat menyusui atau memerah. Tekanan yang diterima oleh ibu bekerja berpotensi memengaruhi jumlah produksi ASI perah. Dengan demikian, salah satu keberhasilan ASI eksklusif adalah dukungan lingkungan sehingga membuat ibu menyusui merasa nyaman dan aliran ASI pun lancar (AnggaSiscarahardian, 2017).

Penerimaan merupakan hal penting yang menjadi focus peningkatan kesadaran diri guna membangun motivasi positif saat proses menyusui. Berdasarkan teori motivasi perlindungan dalam buku Kesehatan Masyarakat dalam Perspektif Sosio antropologi oleh Darwis dan Hikmawati tahun 2017 didasarkan pada empat factor yakni keseriusan, kemungkinan kejadian, atau kerentanan, efektivitas perilaku, pencegahan yang disarankan dan kepercayaan kemampuan diri seseorang (self-efficacy). Dengan hal ini dimungkinkan dapat meningkatkan kepercayaan diri ibu yang akan menjadikan moment menyusui menjadi pengalaman yang lebih menyenangkan sehingga bayi mendapatkan ASI yang cukup sampai usia 2 tahun (Darwis dan Hikmawati, 2017).

Hasil analisis menunjukkan bahwa tidak terdapat hubungan bermakna secara statistik antara tingkat pengetahuan ibu dengan pemberian ASI secara Eksklusif 
pada ibu yang bekerja dengan nilai $\mathrm{P} 0,12$. Dalam penelitian oleh Sisca Rahadian tahun 2017 tentang pemenuhan hak ASI eksklusif di kalangan ibu bekerja menyatakan bahwa pengalaman yang dialami oleh informan berbeda-beda, ada yang didukung oleh rekan-rekan kerja maupun keluarga, namun tidak sedikit yang tidak mendapat dukungan bahkan mendapatikomentar negatif. Sementara itu, informan yang mendapatkomentar positif membuat ibu bekerja dapat memerah dengan lancar (SiscaRahadian, 2017).

Menurut Geuskens, Burdorf dkk tahun 2008 tentang "Work and sick leave among patients with early inflammatory joint conditions". Lingkungan tersebut merupakan salah satu faktor penentu keberhasilan dalam menyusui, yang termasuk pengaruh lingkungan yakni opiniopini keluarga dan teman-teman, kebijakan kesehatan dll (Geuskens dan Burdorf, 2008). Oleh karena itu dapat disimpulkan bahwa dukungan sosial dan evaluasi mengenai keterampilan menyusui dapat memberikan motivasi yang positif kepada ibu untuk memberikan ASI secara eksklusif sampai dengan usia anak 2 tahun.

Hasil analisis menunjukkan bahwa tidak terdapat hubungan bermakna secara statistik antara jenis pekerjaan ibu dengan pemberian ASI secara Eksklusif pada ibu yang bekerja dengan nilai P 0,09. Menurut hasil penelitian Anita Rahmawati dan Bisepta Prayogi tahun 2017 tentang analisis faktor yang mempengaruhi produksi air susu ibu (ASI) pada ibu menyusui yang bekerja. Setiap jenis pekerjaan mempunyai tingkat beban kerja yang berbeda-beda meskipun semua jenis pekerjaan pasti mempunyai kesulitan dan tuntutan masingmasing. Jenis pekerjaan ibu tidak berhubungandengan produksi ASI dalam penelitian inikarena meskipun mempunyai beban kerja yang berbedatetapi semua jenis pekerjaan tersebut menghasilkanpengaruh yang sama terhadap kondisi fisikdan psikologis ibu. Penelitian diambil dari kategori Guru/dosen, Karyawan, Tenaga kependidikan. Hasil menunjukkan 62\% Ibu yang bekerja sebagai karyawan mempunyai produksi ASI $<100 \mathrm{ml} /$ hari tetapi yang menjadi pengaruh dalam hal ini bukan jenis pekerjaan ibu melainkanlama kerja ibu. Karyawan toko dan salon mempunyai waktu kerja melebihi standar waktu kerjafull time yaitu lebih dari 9 sampai lebih dari 10 jam per hari.

Lama kerja dalam penelitian tersebut diukur termasuk dengan waktu perjalanan yang dibutuhkan ibu untuk berangkat dan pulang dari tempat kerja. Demikian didapati hubungan signifikan antara lamakerja dengan produksi ASI 
$(\mathrm{p}=0,001)$. Semakin lamaibu bekerja, semakin sedikit kesempatan ibu untukmenyusui bayinya sehingga frekuensi menyusui menjadi kurang. Hal ini pula menunjukkan ada hubungan frekuensi menyusui langsung ke bayi dengan produksi ASI (Anita dan Prayogi, 2017).

Menurut hasil penelitian oleh Basrowi dkk tahun 2018 mengenai challenges and supports of breast feeding at workplace in Indonesia menemukan $45 \%$ ibu bekerja di Indonesia berhenti menyusui saat bayinya usia 3 bulan karena harus kembali bekerja. Kurangnya fasilitas pendukung laktasi dan program pendukung di tempat kerja serta minimnya pengetahuan mengenai bagaimana melakukan ASI perah (ASIP) juga gencarnya promosi susu formula menjadi alas an utama kelanjutan pemberian ASI secara eksklusif (Basrowi, 2018).

Oleh karenanya dukungan dari tempat kerja sangat dibutuhkan seperti penyesuaian jenis dan waktu kerja serta penambahan waktu istirahat, penyediaan ruang perah ASI dan sarana menyusui (kulkas), lingkungan kerja yang kondusif, penyediaan layanan kesehatan seperti pengadaan penyuluhan dan semacamnya sesuai dengan undangundang Kesehatan No.39/2009 pasal 128, Undang-undang Ketenaga kerjaan No. 13/2009 pasal 83, Peraturan Pemerintah No
33/2012 tentang pemberian ASI Eksklusif dan Peraturan Menteri Kesehatan No. 15 Tahun 2013 tentang Tata Cara Penyediaan Fasilitas Khusus Menyusui dan/atau Memerah Air Susu Ibu (Kemenkes RI, 2015).

Hasil analisis menunjukkan bahwa tidak ada hubungan bermakna secara statistik antara usia ibu dengan pemberian ASI secara Eksklusif pada ibu yang bekerja dengan nilai $\mathrm{P}$ 0,116. Hasil penelitian gambaran hubungan usia produktif dalam pemberian ASI Eksklusif di RSU Budi Kemuliaan diperoleh hasil terbanyak didapatkan usia 20-30 tahun sebanyak 35 responden (68\%). Berdasarkan hasil analisis hubungan antara pemberian ASI Eksklusif ibu bekerja dengan usia produktif ibu bekerja menunjukkan tidak adanya hubungan bermakna secara statistic dengan nilai $\mathrm{P}$ 0,116 namun jika ditinjau kembali terlihat bahwa dari 35 ibu 26 ibu tidak memberikan ASI eksklusif. Saat penelitian didapati bahwa sebagian besar ibu takut jika hanya ASI bayinya masih lapar sehingga diberikan air putih, sari kurma agar sehat, pisang dan susu formula.

Hal ini selaras dengan hasil penelitian oleh Bayu Kurniawan tahun 2013 mengenai determinan keberhasilan Pemberian Air Susu Ibu Eksklusif,bahwa tidak terdapat keterkaitan antarausia produktif terhadap 
pemberian ASI eksklusif pada ibu bekerja.Hasil menunjukkan semakin bertambah usia ibu meningkatkan frekuensi kegagalan pemberian ASI eksklusif. Meskipun hasil ini berbeda dengan beberapa penelitian tentang ASI eksklusif di Australia, Kanada, dan Cina, tetapi hasil dari penelitian oleh Bayu tahun 2013 di Lamongan ini memiliki kesamaan dengan hasil penelitian di Nigeria. Sehingga diberikan kesimpulan bahwa semakin bertambah usia ibu tidak meningkatkan kualitas pemberian ASI kepada bayinya. Pola pengasuhan anak yang tradisional, diajarkan secara turun temurun dari orang tua ibu tidak meningkatkan pengetahuan ibu terhadap pola pemberian ASI eksklusif (Bayu, 2013).

\section{SIMPULAN}

Berdasarkan hasil penelitian dapat disimpulkan bahwa:

1. Hasil uji statistik didapatkan nilai $p$ value 0,04 maka dapat disimpulkan ada hubungan antara jenjang pendidikan terhadap pemberian ASI Eksklusif oleh ibu yang bekerja di RSU Budi Kemuliaan.

2. Hasil uji statistik didapatkan nilai $p$ value 0,04 maka dapat disimpulkan ada hubungan keterampilan ibu menyusui terhadap pemberian ASI ekslusif pada ibu yang bekerja di RSU Budi Kemuliaan.

3. Hasil uji statistik didapatkan nilai $p$ value 0,116 maka dapat disimpulkan bahwa tidak ada hubungan antara usia terhadap pemberian ASI Eksklusif pada ibu yang bekerjadi RSU Budi Kemuliaan.

4. Hasil uji statistik didapatkan nilai $p$ value 0,12 maka dapat disimpulkan tidak ada hubungan antara tingkat pengetahuan terhadap pemberian ASI Eksklusif pada ibu bekerja di RSU Budi Kemuliaan.

5. Hasil uji statistik didapatkan nilai $p$ value 0,09 maka dapat disimpulkan tidak ada hubungan antara jenis pekerjaan terhadap pemberian ASI Eksklusif pada ibu yang bekerja di RSU Budi Kemuliaan.

6. Hasil uji statistik didapatkan nilai $p$ value 0,28 maka dapat disimpulkan tidak ada hubungan antara dukungan social terhadap pemberian ASI Eksklusif pada ibu yang bekerja di RSU Budi Kemuliaan.

\section{UCAPAN TERIMA KASIH}

Kami ucapkan terima kasih kepada Lembaga Kesehatan Budi Kemuliaan yang telah memberikan izin dan Poliknlinik RSU Budi kemuliaan sehingga penelitian ini dapat terlaksana. 
DAFTAR PUSTAKA

Kementrian Kesehatan RI ( 2015 ) Dukung Ibu Bekerja Beri ASI Ekslusif, dipetik November 2018, dari situs Departemen Kesehatan RI: www.depkes.go.id/article

Pusat Data Indonesia. (2018). Profil Kesehatan Indonesia Tahun 2017. diunduh Januari 1, 2019, from Pusat Informasi Data Indonesia: http://www.pusdatin.kemkes.go.id

Kemenkes RI. 2014. Pedoman Gizi Seimbang.

Orlowski, Michelle dan S. Sarao,Manbeer. (2018, Desember 16). Physiology Human Hormone. USA: National Center for Biotechnology Information. Diakses pada 1 Mei 2019, from National Library of Medicine at www.ncbi.nlm.nih.

Pusat Data Indonesia. (2018). Profil Kesehatan Indonesia Tahun 2017. diunduh Januari 1, 2019, from Pusat Informasi Data Indonesia: http://www.pusdatin.kemkes.go.id

Basrowi, Ray Wagiu., dkk. 2018. Challenges and supports of breastfeeding at workplace in Indonesia. Pediatric Gastroenterology, Hepatology and Nutrition. Diunduh pada 2 Juli 2019 dari situs https://scholar.ui.ac.id/en

Handayani, Lina.,dkk. 2016. The Association between Breastfeeding Technique and Knowledge with Exclusive Breastfeeding. Yogyakarta: Jurnal Kedokteran dan Kesehatan Indonesia. Diunduh pada 25Juli 2019 dari situshttps://media.neliti.com/media

LumonggaLubis, Namora. 2011. Memahami dasar-dasar konseling dalam teori dan praktik. Jakarta: Kencana Prenada Media Group. Dicari pada Juli 28, 2019, from https://books.google.co.id/books

Darwis dan Mas'ud, Hikmawati. 2017. Kesehatan Masyarakat dalam
Perspektif Sosioantropologi.

Makasar: CV Sah Media.Dicari pada Juli 28, 2019, from https://books.google.co.id/books

Aditya Rahman, R. Topan. 2015. Analisis Statistik Penelitian Kesehatan.Bogor: InMedia.

Notoatmodjo, Soekidjo. 2014. Metodologi Penelitian Kesehatan. Jakarta: Rineka Cipta. 